\title{
Preserving Spontaneous Respiration with High Dose Dexmedetomidine Infusion for Complex Airway Instrumentations in Neonates. A Case Report
}

\author{
Nur Hafiizhoh A Hamid ${ }^{1}$ and HI Hee ${ }^{1,2 *}$ \\ ${ }^{1}$ Department of Paediatric Anaesthesia, KK Women's and Children's Hospital, Singapore \\ ${ }^{2}$ DUKE NUS Graduate Medical School, Singapore
}

Submission: December 13, 2018; Published: January 11, 2019

*Corresponding author: Betül Kocamer Şimşek, Faculty of Medicine, Department of Anesthesiology and Reanimation, Sanko University,Turkey

\begin{abstract}
Inhalational anesthesia has been a standard practice for neonates to undergo airway procedures. Nevertheless, recent animal studies have shown that volatile anesthetics and propofol may induce neuroapoptosis in neonatal brains. A high dexmedetomidine infusion rate could obtund the airway reflexes while preserving spontaneous respiration and maintaining airway patency during simulating airway procedures without affecting hemodynamic stability. This alternative technique is particularly useful in neonates whom respiratory reserve is low and neurodevelopment is a concern as well as when poor laryngeal visualization had precluded the use of local topicalization over the parapharyngeal structures where multiple airway instrumentations will be performed. We described usage of high dose of dexmedetomidine infusion as the main anesthetic agent during complex airway instrumentations in two neonates with underlying pulmonary hypertension, where maintenance of spontaneous respiration is the mainstay airway strategy.
\end{abstract}

Keywords: Airway; Bronchoscopy; Dexmedetomidine; Neonate; Pulmonary Hypertension

\section{Introduction}

Dexmedetomidine (Precedex $®$, Hospira, Lake Forest, IL, USA) is a potent alpha2-adrenoceptor agonist that provides sedation and analgesia with preservation of respiratory drive and limited hemodynamics effect. We report 2 cases where high dose of dexmedetomidine infusion was used to provide deep anesthesia condition for a series of airway instrumentations in neonates with underlying pulmonary hypertension.

\section{Case Summary}

\section{Case 1}

A $2.24 \mathrm{~kg}$ term baby with tracheoesophageal fistula presented for emergency rigid bronchoscopy, isolation of fistula, right thoracotomy and primary anastomosis at 22 hours of life. His premorbid condition included right congenital pulmonary airway malformation, left hypoplastic lung, atrial septal defect, patent ductus arteriosus, hypoplastic left heart, mild pulmonary hypertension and aberrant right subclavian artery. He was intubated and sedated with morphine infusion in the Intensive Care Unit (ICU). Intravenous dexmedetomidine was initiated upon arrival in operating theatre at an infusion rate of $0.5 \mathrm{mcg} /$ $\mathrm{kg} /$ hour and increased to $1.2 \mathrm{mcg} / \mathrm{kg} /$ hour within 15 minutes. After application of standard monitoring, anesthesia was induced with sevoflurane up to $1.5 \%$ with a fresh gas flow of $4 \mathrm{~L} / \mathrm{min}$ oxygen via an Ayres T-piece breathing circuit. Endotracheal Tube (ETT) was removed and airway was topicalized with $5 \mathrm{mg}$ of $1 \%$ lidocaine. Sevoflurane was turned off prior to airway procedure. Dexmedetomidine infusion $(1.0-1.2 \mathrm{mcg} / \mathrm{kg} /$ hour $)$ and morphine infusion $(20 \mathrm{mcg} / \mathrm{kg} /$ hour $)$ were continued. Rigid bronchoscopy revealed a large fistula at the carina. Direct laryngoscopy to facilitate rigid bronchoscope advancement technique was utilized in attempt to pass through a $2 \mathrm{~mm}$ Forgarty catheter to occlude the fistula. The Forgarty cannulation was successful on third attempts. Tracheal was subsequently intubated with uncuff ETT $3.5 \mathrm{~mm}$. Right thoracotomy and primary anastomosis of tracheoesophageal fistula was completed with continuation of the dexmedetomidine and morphine infusion titrated per requirement throughout the surgery.

\section{Case 2}

A $2.3 \mathrm{~kg}$, 7 days old term baby with Pierre Robin sequence was brought in for emergency intubation and tracheostomy. He had history of failed intubation attempts in his first week of life and severe desaturation with bradycardia due to obstructed airway. He was put on nasal CPAP. His premorbid condition includes CHARGE syndrome with large ventral septal defect, double outlet right ventricle, atrial septal defect and moderate pulmonary hypertension. On arrival in operating theatre, standard monitoring 
was applied. Dexmedetomidine infusion was initiated at a rate of $0.5 \mathrm{mcg} / \mathrm{kg} / \mathrm{hour}$ and increase to $1.0 \mathrm{mcg} / \mathrm{kg} / \mathrm{hour}$ within 15 minutes. Anesthesia was induced with $6 \%$ sevoflurane inhalation via Ayres $\mathrm{T}$ piece breathing system with a fresh gas flow of $6 \mathrm{~L} /$ min oxygen. Sevoflurane was reduced to end tidal of $0.5-1 \%$ when airway instrumentations commenced. Video laryngoscopy with glidescope revealed Cormack Lehane grade 3 glottis followed by two failed intubation attempts. Size 1 laryngeal mask airway (LMA) was inserted and fibreoptic bronchoscopy was performed through the LMA. After multiple attempts, a $3.0 \mathrm{~mm}$ microlaryngeal ETT was successfully railroaded into the trachea through the flexible bronchoscope. Tracheostomy proceeded thereafter. Airway topicalization was not done due to poor glottis view.

In both cases, there was no desaturation. Spontaneous breathing was achieved with no straining, coughing, gagging or movement throughout airway instrumentations. There was no hemodynamic change observed with blood pressure and heart rate remaining within $5-10 \%$ range of the baseline. Both patients were sent back to ICU intubated after their surgery.

\section{Discussion}

Dexmedetomidine is a highly selective alpha2-adrenoceptor agonist. While approval of dexmedetomidine use for children has not been given for any indication, it has gained popularity in pediatric application due to its favorable sedative property, insignificance hemodynamic disturbance, preservation of respiratory function and its potential neuroprotective effect in developing brain.

This is the first case report where dexmedetomidine infusion at a higher dose regime of $1.0-1.2 \mathrm{mcg} / \mathrm{kg} /$ hour was used to provide a quiescent condition for a series of repeated airway instrumentations in neonates. This is particularly useful when poor laryngeal visualization precludes topicalization of the airway. In both cases, spontaneous respiration was the mainstay of airway strategy to prevent respiratory embarrassment. In the first instance was to prevent forced ventilation through the fistula and ensuing gastric distension, the second instance to prevent of loss of airway. The airway procedures performed included rigid bronchoscopy, bronchoscopy assisted Forgarty catheter insertion, video-laryngoscopy, tracheal intubation via flexible bronchoscopy and tracheostomy. The use of a larger dose of dexmedetomidine in our neonates did not result in hypotension or bradycardia, hemodynamic stability was maintained.

Neither loading nor boluses of dexmedetomidine, propofol, ketamine or opiates were given in our cases. These were in contrast to Seybold JL et al. [1], where co-infusion of dexmedetomidine at $2.5 \mathrm{mcg} / \mathrm{kg} / \mathrm{hour}$ and propofol at $200-250 \mathrm{mcg} / \mathrm{kg} / \mathrm{min}$ with additional dexmedetomidine boluses in the increments of 0.25 to $1 \mathrm{mcg} / \mathrm{kg}$ were required to obtund airway reflexes for laryngoscopy and rigid bronchoscopy prior to tracheal extubation in small children [1]. Another report by Syukry \& Kennedy [2] described intermittent boluses of dexmedetomidine at $1 \mathrm{mcg} /$ $\mathrm{kg} / \mathrm{min}$ per boluses (total required boluses given were $2-5 \mathrm{mcg}$ / $\mathrm{kg}$ ) as the primary anesthetic agent for direct laryngoscopy and bronchoscopy in a tropicalized airway of 4 infants [2]. Jeong Soo Lee et al. [3] had loaded $0.5 \mathrm{mcg} / \mathrm{kg}$ dexmedetomidine, followed by a higher infusion rate of $1.0-1.5 \mathrm{mcg} / \mathrm{kg} /$ hour with intermittent ketamine boluses in young infant with 1-month history of VSD repair coming for rigid bronchoscopy [3]. As there had been concern regarding possible elevation of pulmonary artery pressure and pulmonary vascular resistance with rapid administration of dexmedetomidine [4,5], we had omitted dexmedetomidine loading dose and intermittent boluses in our patients who has mild to moderate pulmonary hypertension. Though Friesen et al. \& Nathan et al. [6,7] had subsequently demonstrated a safety use of dexmedetomidine in pediatric patient with pulmonary hypertension [6,7]. In addition, our neonates were exposed to noxious stimulus of airway manipulation and at risk of hypoxia, factors known to precipitate increment of pulmonary vascular resistance and worsen pulmonary hypertension in the postnatal period. In agreement with all these pediatric reports, our technique had also provided optimal surgical condition while preserving respiratory drive in neonates with insignificance hemodynamic effects.

In conclusion, we described use of higher dexmedetomidine infusion rate as the main anesthetic agent during a series of airway instrumentations in neonates with pulmonary hypertension where spontaneous respiration was the mainstay airway strategy. This technique preserves spontaneous respiration, obtunds airway reflexes with little hemodynamic effect. This case report will add to literature broadening application of dexmedetomidine in pediatric practice.

\section{Acknowledgements}

Department of Paediatric Anaesthesia, KK Women's and Children's Hospital, Singapore

\section{Disclosures}

Parental consent obtained.

\section{References}

1. Seybold JL, Ramamurthi RM, Hammer GB (2007) The use of dexmedetomidine during laryngoscopy, bronchoscopy, and tracheal extubation following tracheal reconstruction. Pediatric Anesthesia 17(12): 12121214.

2. Syukri M, Kennedy KI (2007) Dexmedetomidine as total intravenous anaesthetic in infants. Pediatric Anesthesia 17(6): 581-583.

3. Lee JS, Park SJ, Min KT (2014) Dexmedetomidine for rigid bronchoscopy in an infant with tracheal web after ventricular septal defect patch repair. Yonsei Med Journal 55(2): 539-541.

4. Lazol JP, Lichtenstein SE, Jooste EH, Shiderly D, Kudchadker NA, et al. (2010) Effect of dexmedetomidine on pulmonary artery pressure after congenital cardiac surgery: A pilot study. Pediatr Crit Care Med 11(5): 589-592.

5. Jooste EH, Muhly WT, Ibinson JW, Suresh T, Damian D, et al. (2010) Acute hemodynamic changes after rapid intravenous bolus dosing of dexmedetomidine in pediatric heart transplant patients undergoing routine cardiac catheterization. Anesthesia and Analgesia 111(6): 1490-1496. 
6. Friesen RH, Nichols CS, Twite MD, Cardwell KA, Pan Z, et al. (2013) The hemodynamic response to dexmedetomidine loading dose in children with and without pulmonary hypertension. Anesthesia and Analgesia 117(4): 953-959.
7. Nathan AT, Marino BS, Brian H, Nicholson SC (2008) Novel use of dexmedetomidine in a patient with pulmonary hypertension. Pediatric Anesthesia 18(8): 782-784.

This work is licensed under Creative Commons Attribution 4.0 License

DOI: 10.19080/JAICM.2019.08.555733

\section{Your next submission with Juniper Publishers} will reach you the below assets

- Quality Editorial service

- Swift Peer Review

- Reprints availability

- E-prints Service

- Manuscript Podcast for convenient understanding

- Global attainment for your research

- Manuscript accessibility in different formats

(Pdf, E-pub, Full Text, Audio)

- Unceasing customer service

Track the below URL for one-step submission https://juniperpublishers.com/online-submission.php 